БАЖИН Игорь Иванович - доктор технических наук, доктор социологических наук, профессор (bazhin41@gmail.com)

\title{
ПРИНЦИП СОБОРНОСТИ В ПРИОРИТЕТНЫХ ПРОЕКТАХ СТРАТЕГИИ РОССИИ: РЕГИОНАЛЬНЫЙ АСПЕКТ
}

\begin{abstract}
Аннотация. Прорыв в экономике, сформулированный президентом РФ как основная задача стратегии России, может быть достигнут лишь совместной сплоченной работой общества, власти и предпринимательства. В этом усматривается акцент на исконно русском понятии - соборности. Именно соборность, проявленная при замене рухнувшей партийной системы созданием комплекса законов, восполняющих правовой вакуум в исполнительном механизме государственного управления, обеспечила сохранение государственности, поставленной на грань разрушения в 90-е гг. прошлого века.

В то же время обеспечение правовой и политической целостности государства не привело еще к значимому прорыву в экономике. Пока еще не заработал в полную силу механизм системной интеграции России в сфере экономики, способный превратить нашу страну в единый организм, в котором эффекты синергии обеспечивают достижение весомых социально значимых результатов при использовании достаточно ограниченных ресурсов. Можно утверждать, что системная интеграция России возможна лишь на основе построения комплекса приоритетных проектов, синергически связывающих все регионы России путем достижения оптимального баланса их различий и общности.
\end{abstract}

Ключевые слова: экономический прорыв, соборность, системная интеграция, синергия, баланс единства и различий

$\mathrm{B}$ Послании Федеральному собранию от 1 марта 2018 г. президент РФ Владимир Путин отметил: «Изменения в мире носят цивилизационный характер, и масштаб вызова требует от нас такого же сильного ответа. И мы готовы дать этот ответ. Мы готовы к серьезному прорыву. Мы можем это сделать на сплоченности российского общества и на колоссальном потенциале нашего талантливого, творческого народа» ${ }^{1}$.

Ответом на упомянутые вызовы, определяющим национальные цели и стратегические задачи развития России, стал майский указ 2018 г. Президента РФ, в котором ключевыми целями заявлены «осуществление прорывного научно-технологического и социально-экономического развития Российской Федерации... увеличение численности населения страны, повышение уровня жизни граждан, создание комфортных условий для их проживания, а также условий и возможностей для самореализации и раскрытия таланта каждого человека» ${ }^{2}$.

В соответствии с указанными национальными целями указ президента определяет направления, по которым правительству РФ совместно с органами государственной власти субъектов РФ предписано разработать соответствующие национальные проекты (программы). Здесь важным аспектом является участие регионов в разработке приоритетных национальных проектов. Это полностью соответствует заявлению Владимира Путина на заседании Госсовета по приоритетным направлениям работы регионов в апреле 2018 г., что выполнение ключевой задачи в стратегическом развитии страны - провести прорыв в экономике - возможно только совместными усилиями, сплоченной работой общества, власти и предпринимательства.

В этом заявлении президента страны просматривается глубинная связь с

\footnotetext{
${ }^{1}$ http://kremlin.ru/events/president/news/56957

2 http://kremlin.ru/events/president/news/57425
} 
одним из ключевых понятий русской философии - соборностью. Термин не имеет аналогов в других языках, является исконно русским и означает свободное духовное единение людей (как в церковной жизни, так и в мирской общности).

Осмысление понятия соборности применительно к стратегии развития региона представляется весьма важным в свете обозначенного президентом России вектора развития нашей страны. На интернет-ресурсе «Понятия и категории» 1 приведены трактовки термина «соборность» различными авторами. Несмотря на определенные терминологические различия, в этих трактовках можно выделить основополагающий принцип соборности - сочетание свободы и единства.

Казалось, здесь сочетается несочетаемое, поскольку «свобода» и «единство»это два самостоятельных принципа. Более того, единение подразумевает связь, т.е. определенную несвободу. Но в этом сочетании и состоит чудо российской сборности, не раз в истории позволявшей возрождаться стране, что называется, из пепла. Достаточно вспомнить призыв: «Купно за едино!», произнесенный более 400 лет назад нижегородским купцом Кузьмой Мининым и приведший к победе над смутой, ставящей страну на грань гибели.

Если говорить о принципе свободы, то соборность - это и следствие свободы человека как личности, и основа свободы личности. Однако здесь нет ничего общего с концепцией либерализма, поскольку в соборности общее благо складывается не «само собой», стихийно-хаотично (вспомним пресловутое «рынок сам все вывезет!»), а представляет собой результат совместной целенаправленной деятельности свободных людей добровольно «купно за едино» идущих к намеченной цели. То есть, экономическая свобода личности и общества в целом - это не бессовестный и бессердечный либерализм, для которого нормой является вседозволенность, ограничиваемая лишь жестким (нередко жестоким) сопротивлением мафиозно организованных «братьев по либеральному классу», определивших деньги как эталон покупательной способности и средство осуществления вседозволенности.

Экономическая свобода - это, прежде всего, высокая степень организованности (т.е. единения) общества, базирующаяся на необходимости и открытой возможности добросовестно трудиться и позволяющая на этой основе в полной мере удовлетворять материальные и духовные потребности членов такого высокоорганизованного сообщества.

Апологеты так называемой либеральной идеи давно (к счастью, безуспешно) подвергают критике упомянутый принцип единства, высокой организованности. Диапазон и накал страсти этой критики простирается от мягкого («государству нужно снизить уровень регулирования экономических процессов, предоставив это регулирование свободному рынку») до жесткого и одиозного («в России установлена диктатура правления Путина»).

Хотелось бы напомнить таким критикам, с каким трудом преодолевала страна выдвинутый в 1990-е гг. известный лозунг, обращенный к регионам России: «Берите суверенитета столько, сколько сможете проглотить!» Напомнить о шествии по стране «парада суверенитетов» и о тех ужасающих последствиях, к которым привел этот «парад». Это обращение к абсолютной свободе привело систему государственного управления в состояние, практически близкое к потере управляемости. На наш взгляд, это произошло в первую очередь по причине структурных изменений системы государственного управления, потери необходимых структурных компонентов системы управления, что разрушило

${ }^{1}$ http://ponjatija.ru/taxonomy/term/681 
целостность самого процесса управления и создало угрозу разрушения, потери государственности.

Порожденные этой свободой (точнее, «вольницей», «махновщиной») структурные дефекты системы управления [Бажин 2009; Бажин, Маленькая 2010] вызвали в нашей стране один из известных кризисов политического развития - кризис проникновения. Этот кризис заключается в снижении способности государственного управления проводить свои директивы в различных областях общественной жизни, в искажении смысла принимаемых государственных решений на уровне местных социальных структур, в отторжении политической элитой инициируемых центром инноваций, в ориентации населения в большей степени на региональные и национальные обычаи и нормы, а не на решения центра.

С большим напряжением моральных и духовных сил, с мобилизацией лучших интеллектуальных ресурсов в течение немалого времени удалось ввести правовое поле страны в лоно принципа единства, чем, по сути, была ликвидирована угроза реального (физического) распада России, преодолен кризис политического развития.

Деятельность второго президента России В. Путина в начальный период в первую очередь была связана с построением вертикали исполнительной власти, а по сути - с созданием дееспособной исполнительной системы. Это позволило снизить уровень хаоса, предотвратить опасные процессы деструкции, грозящие, в конечном счете, распадом России как целостного государства, как целостной системы управления.

Значительный интерес представляет то, какими структурными средствами, какими механизмами создавалась, по сути, новая исполнительная система, призванная заменить рухнувшую партийную систему, достаточно эффективно обеспечивавшую в свое время работу исполнительного механизма государственного и местного управления. Практика управления в первые годы деятельности В.В. Путина показала, что многочисленные попытки добиться эффективности исполнительной системы путем структурных и кадровых решений не давала желаемых результатов: по-прежнему оставалась достаточно острой проблема неисполнения законов, носящих характер рамочных, в самой сути которых отсутствовал алгоритм, обеспечивающий гарантии их исполнения. Многие стороны государственной деятельности, особенно деятельности на местах, слабо регламентировались, оставляя достаточную долю хаоса, неоднородности и неоднозначности в инвариантных управленческих действиях в полном соответствии с известным либеральным лозунгом: «Что не запрещено, то разрешено».

На наш взгляд, серьезным успехом периода деятельности второго президента является возникшее понимание, что эффективный ранее исполнительный механизм партийной системы в новых условиях может быть восполнен единственно возможным способом - правовой регламентацией, созданием системы законов «второго эшелона», т.е. законов, восполняющих правовой вакуум в исполнительном механизме государственного управления. Именно эта система законов, регламентирующих, «алгоритмизирующих» управленческие действия, и призвана была стать новым исполнительным механизмом системы управления в рыночных условиях. Исполнительную административно-командную партийную систему призван заменить не менее эффективный правовой механизм, задачей которого является путем наращивания структурной правовой информации снизить энтропию, хаос системы управления до уровня, обеспечивающего высокую эффективность исполнительной системы.

Именно в этом ключе, на наш взгляд, следует понимать появившиеся в свое 
время законы, к которым в первую очередь можно отнести Жилищный кодекс РФ; федеральные законы N 79-Ф3 «О государственной гражданской службе Российской Федерации»; N 131-Ф3 «Об общих принципах организации местного самоуправления в Российской Федерации»; N 94-Ф3 «О размещении заказов на поставки товаров, выполнение работ, оказание услуг для государственных и муниципальных нужд» и развившие его федеральные законы N 223-Ф3 «О закупках товаров, работ, услуг отдельными видами юридических лиц» и N 44-Ф3 «О контрактной системе в сфере закупок товаров, работ, услуг для обеспечения государственных и муниципальных нужд» и некоторые другие. Заметим попутно, что эти законы в определенной мере создали правовые механизмы предотвращения коррупции в органах власти.

Таким образом, построение правового поля жизнедеятельности страны и стало одним из проявлений соборности России на этом этапе ее развития.

Вместе с тем, построив в значительной мере правовое единство России, обеспечив правовую и политическую целостность государства, руководство страны не в полной мере достигло того же в экономике. Отдаваемое нередко правительственными структурами России предпочтение либеральным идеям, идеям «безграничной свободы рынка» не позволило пока добиться значительных успехов в росте благосостояния российского общества. Пока еще не заработал в полную силу механизм системной интеграции России в сфере экономики, способный превратить нашу страну в единый организм, в котором проявляются эффекты синергии, позволяющие достигать весомых социально значимых результатов при использовании достаточно ограниченных ресурсов.

Системная же интеграция России, способная обеспечить прорыв в экономике, на наш взгляд, возможна лишь на основе построения комплекса приоритетных проектов, синергически связывающих все регионы России путем достижения оптимального баланса их различий и общности. Заметим, что еще в 2005 г. была предложена концепция стратегической перспективы России [Бажин 2005], в основу которой были футуристически положены компоненты, ставшие впоследствии национальными проектами России, обозначившими стратегические рубежи развития страны на многие годы.

Упомянутый баланс различий и общности базируется на оценке соотношения в системе уровня разнообразия элементов (неопределенности) и информации, структурирующей систему [Бажин 2007]. Таким образом, истинное состояние системы существенно зависит от соотношения этих двух составляющих: если преобладает элементная информация, то система более склонна к хаосу, к диссипации, к распаду. Если «побеждает» структурная информация, то в значительной мере система определенна, предсказуема и, добавим, управляема. Как отмечает лауреат Нобелевской премии Илья Пригожин, «между устойчивостью, обеспечиваемой связью, и неустойчивостью из-за флуктуаций имеется конкуренция. От исхода этой конкуренции зависит порог устойчивости» [Пригожин, Стенгерс 2000].

В исследованиях по проблемам синергетики описаны стадии перехода системы от состояния предельного хаоса и максимальной энтропии к состоянию жесткой детерминации и нулевой энтропии [Бажин 2008]. Опираясь на метод Парето, оптимальным соотношением детерминации и свободы (энтропии) можно считать показатель $80 \%$ : 20\%. После преодоления этой точки в наращивании детерминации система быстро теряет свои адаптивные свойства и входит в состояние полной детерминации, при котором она может существовать только в строго стабильных условиях. В случае их изменения происходит ее разрушение и скачкообразный переход в состояние хаоса. Это характерно, например, для тоталитарных общественных систем. В отличие от них, адап- 
тивно развивающийся социум, достигнув оптимального соотношения, имеет возможность перейти на следующий иерархический уровень развития, начать формировать между элементами прежнего уровня новые информационные связи.

Таким образом, применительно к стратегическим направлениям развития региона целесообразно ключевую опору (80\%) делать на федеральные приоритетные проекты, чем обеспечивается системное единство, требуемая целостность экономического развития России в целом и региона как неразрывной части страны. Немалую роль здесь играет совокупность указов Президента РФ «Об оценке эффективности деятельности органов исполнительной власти субъектов Российской Федерации», начиная с указа от 28.06.2007 № $825^{1}$ до указа от 14.11.2017 № 5482, содержащих четко выраженные критерии, позволяющие предметно судить об истинной эффективности (сопоставляемой с другими регионами) деятельности региональной властной структуры, заключающейся в получении социально значимых результатов на уровне региона или муниципального образования.

Решающую роль в системной интеграции России играют майские указы Президента РФ (2012 г. и 2018 г.), определившие в виде документов прямого действия приоритетные направления развития страны. И компоненты региональных стратегий, безусловно, должны содержать и направления, и соответствующие параметры указов в составе $80 \%$ содержательной части.

Дополнительно заметим, что на это направлен и федеральный закон от 28 июня 2014 г. N 172-Ф3 «О стратегическом планировании в Российской Федерации», требующий при разработке региональной стратегии учитывать стратегические приоритеты развития РФ, определенные в действующих стратегических документах федерального уровня.

В то же время необходимо помнить, что в соответствии с известным законом необходимого разнообразия, сформулированным У.Р. Эшби [Эшби 1959], формирование разнообразных функций и структур, находящихся на более высоких уровнях социальных систем, возможно только при условии ограничения разнообразия нижележащего уровня. Фактически рост разнообразия системы более высокого ранга обеспечивается за счет его уменьшения в подчиненных, периферийных системах. Так, увеличение разнообразия, в частности, полномочий регионального органа управления неизбежно приводит к снижению разнообразия на уровне муниципальных образований, что лишает их, например, полномочий, предусмотренных федеральным законом N 131Ф3, и может вызвать негативные последствия (игнорирование местных условий, потеря инициативы органами МСУ и т.п.). Эти рассуждения помогают подойти к важной в управлении изменениями и в оптимизации организационных структур проблеме поисков оптимального соотношения свободы и детерминации во взаимоотношениях граждан (общества) и государства, отдельного индивида и корпорации (сословия, класса, коллектива). Эти представления помогают понять, что безграничная свобода, как и жесткий контроль, эволюционно не оправданны. В связи с этим при наделении полномочиями властных и хозяйствующих структур необходимо устанавливать уровень свободы,

\footnotetext{
1 Указ Президента РФ от 28.06.2007 № 825 «Об оценке эффективности деятельности органов исполнительной власти субъектов Российской Федерации». Доступ: http://www.garant.ru/products/ipo/ prime/doc/91419/

2 Указ Президента РФ от 14.11.2017 №548 «Об оценке эффективности деятельности органов исполнительной власти субъектов Российской Федерации». Доступ: http://www.garant.ru/products/ipo/ prime/doc/71709662/
} 
не превосходящий предел связности, обеспечивающий целостность системы, ее качественную определенность.

Учитывая это обстоятельство, необходимо добиться, чтобы $20 \%$ содержательной части стратегии развития региона (отдельные региональные программы и проекты, параметры в региональных компонентах федеральных приоритетных проектов) было посвящено региональным особенностям, отличиям, региональным обычаям и предпочтениям. Именно при таком условии будет обеспечена адаптация общего стратегического развития России к особенностям региона, что призвано обеспечить беспрепятственное и эффективное, поддерживаемое членами регионального сообщества практическое осуществление стратегических установок (вспомним: «купно за едино»).

В этом отношении отметим необходимость социального участия в этой работе экспертов-исследователей, работающих в различных областях социогуманитарного знания, уже на стадии формирования заданий на социально значимые программы и проекты для оценки их экосоциокультурных последствий [Бажин 2009]. При этом важно перенести акценты с ведомственно-отраслевого на территориально-региональный анализ замыслов и издержек от управленческих решений. Это позволит сместить критерии приоритетности в их оценке с количественных показателей экономической выгоды к качественным - экосоциокультурологическим, непосредственно связанным с повседневной жизнью людей. Немаловажно к тому же исследовать социальные и социально-психологические механизмы выработки решений, отработать научно обоснованную технологию их обеспечения социально значимой информацией.

В качестве примера такого подхода упомянем разработанный и представленный на обсуждение экспертному сообществу и широкой общественности проект Стратегии Нижегородской области до 2035 года, который в своей содержательной и структурной основе содержит упомянутый принцип соборности. Это, прежде всего, заключается в том, что в структуре проекта Стратегии Нижегородской области до 2035 г. содержатся все приоритетные направления, соответствующие национальным целям, установленным майским 2018 г. указом Президента РФ, определяющим стратегию развития России. Более того, в каждом из направлений опора идет в первую очередь на соответствующий приоритетный федеральный проект с согласованными региональными параметрами, интегрированными в общую стратегию страны. В этом проявилась соборность как иерархически наивысшая суперсистема во взаимовложенности суперсистем, образующих человеческое сообщество.

Нормативно-правовой основой разработки Стратегии социально-экономического развития Нижегородской области до 2035 года явились федеральный закон от 28 июня 2014 г. N 172-Ф3 «О стратегическом планировании в Российской Федерации» и закон Нижегородской области от 3 марта 2015 г. N 24-3 «О стратегическом планировании в Нижегородской области».

При разработке Стратегии социально-экономического развития Нижегородской области до 2035 года учтены, как того требует федеральный закон, стратегические приоритеты развития Российской Федерации, определенные в действующих стратегических документах федерального уровня.

В то же время для обоснованного учета региональных особенностей, отличий, анализа региональных обычаев и предпочтений к разработке проекта Стратегии были привлечены ведущие региональные эксперты - представители бизнеса, научных и общественных организаций, жители, имеющие активную жизненную позицию, для чего было создано 18 экспертных групп по приоритетным направлениям развития Нижегородской области. 
Был организован постоянный диалог с экспертами, проведены более 50 заседаний, в которых участвовали около 400 чел. В результате обеспечена всесторонняя проработка проблем, перспектив развития Нижегородской обл., определены основные задачи и стратегические инициативы, реализация которых позволит региону добиться поставленных целей - в частности, увеличения ВРП на душу населения к 2035 г. не менее чем в 3 раза в сопоставимых ценах.

Стратегия разрабатывалась с учетом анализа достигнутого уровня развития региона в результате реализации предыдущей Стратегии. Это позволило учесть ее недостатки и сохранить преемственность тех направлений развития, в которых удалось достичь существенных положительных результатов. Особенностью Стратегии стало включение в ее состав раздела о пространственном развитии Нижегородской обл.

Широкое общественное обсуждение проекта Стратегии осуществляется в рамках отраслевых стратегических сессий по следующим темам:

- IT / Цифровое общество;

- Инфраструктура / Энергетика;

- Социальная политика / Демография / Активное долголетие;

- Промышленность / Наука;

- Предпринимательство / Инвестиции;

- Здоровье / Здравоохранение / Спорт;

- Гражданское общество / Власть;

- Молодежь;

- Комфортная среда /Архитектурный облик / Объекты культурного наследия;

- Культура / Туризм / 800-летие Нижнего Новгорода.

Суждения, критика, конкретные предложения по корректировке структуры и параметров, а также редакционной правке текста Стратегии концентрируются в экспертном центре, организованном при губернаторе Нижегородской области, с целью детального анализа, обсуждения и внесения соответствующих изменений в текст проекта Стратегии.

Окончательная редакция Стратегии будет осуществлена и представлена для утверждения с учетом принятых корректировок. Именно такой поход, на наш взгляд, способен обеспечить принятие стратегических установок региональным сообществом для реализации Стратегии Нижегородской области «купно за едино».

Таким образом, совокупность приоритетных направлений, изложенных в майских указах Президента РФ, реализующихся в соответствующих приоритетных проектах федерального уровня, обеспечивают при соблюдении принципа соборности в региональных стратегиях системную интеграцию России в единый социально-экономический организм, способный осуществить долгожданный прорыв в экономике и вывести нашу страну на принципиально новый, высокий уровень социального развития.

\section{Список литературы}

Бажин И.И. 2005. Концепция стратегической перспективы России. Государственная служба. № 3. С. 117-124.

Бажин И.И. 2007. Механизмы адаптации в социальной инноватике государственного управления. - Государственная служба. № 1. С. 29-37.

Бажин И.И. 2008. Социальная инноватика регионального и муниципального управления: монография. Н. Новгород: Изд-во ВВАГС. 260 с.

Бажин И.И. 2009. Социальная инноватика в системе управления регионом: монография. Н. Новгород: Изд-во ВВАГС. 309 с.

Бажин И.И., Маленькая М.А. 2009. Формирование структурного меха- 
низма государственного и муниципального управления переходного периода в России. - Вестник Нижегородского университета им. Н.И. Лобачевского. № 5. C. 312-317.

Пригожин И., Стенгерс И. 2000. Порядок из хаоса. Новый диалог человека с природой. М.: Эдиториал УРСС. 431 с.

Эшби У.Р. 1959. Введение в кибернетику. М.: Иностранная литература. 432 с.

BAZHIN Igor' Ivanovich, Dr.Sci. (Tech. Sci.),Dr.Sci. (Soc.), Professor (bazhin41@gmail.com)

\title{
PRINCIPLE OF SOBORNOST' IN PRIORITY PROJECTS OF THE RUSSIA'S STRATEGY: REGIONAL ASPECT
}

\begin{abstract}
The breakthrough in the economy formulated by the President of the Russian Federation as the main goal of Russia's strategy can be achieved only by a united work of society, power and entrepreneurship. Here we can see an accent on the primordially Russian concept - collegiality (sobornost'). It is sobornost', manifested in the replacement of the collapsed party system by creating a set of laws that fill the legal vacuum in the executive mechanism of state administration, ensured the preservation of statehood, put on the brink of destruction in the 1990s.

At the same time, ensuring the legal and political integrity of the state has not yet led to a significant breakthrough in the economy. The mechanism of system integration of Russia in the sphere of economy, capable of transforming our country into a single organism, in which the effects of synergy provide socially significant results with the use of rather limited resources, has not yet begun to work at its full potential. One can argue that Russiass system integration, which can provide a breakthrough in the economy, is possible only on the base of building a set of priority projects that are synergistically linking all regions of Russia by achieving an optimal balance of their differences and commonalities.
\end{abstract}

Keywords: economic breakthrough, collegiality (sobornost'), system integration, synergy, balance of unity and differences 